Ussama Makdisi, Artillery of Heaven. American

Missionaries and the Failed Conversion of the Middle

East

Ithaca - New York, Cornell University Press, 2008, 262 p.

André Georges Sleiman

URL : http://journals.openedition.org/assr/19603

DOI : $10.4000 /$ assr. 19603

ISSN : $1777-5825$

Éditeur

Éditions de l'EHESS

Édition imprimée

Date de publication : 1 octobre 2008

Pagination : 163-274

ISBN : 978-2-7132-2192-7

ISSN : 0335-5985

Référence électronique

André Georges Sleiman, « Ussama Makdisi, Artillery of Heaven. American Missionaries and the Failed Conversion of the Middle East », Archives de sciences sociales des religions [En ligne], 144 I octobredécembre 2008, document 144-43, mis en ligne le 04 février 2009, consulté le 21 septembre 2020. URL : http://journals.openedition.org/assr/19603; DOI : https://doi.org/10.4000/assr.19603

Ce document a été généré automatiquement le 21 septembre 2020.

(c) Archives de sciences sociales des religions 


\title{
Ussama Makdisi, Artillery of Heaven. American Missionaries and the Failed Conversion of the Middle East
}

\author{
Ithaca - New York, Cornell University Press, 2008, 262 p.
}

\section{André Georges Sleiman}

Le nouvel ouvrage d'Ussama Makdisi relate l'histoire dramatique du premier converti arabe au protestantisme américain pendant les années 1820. Il s'agit d'un jeune chrétien maronite du Mont-Liban, As'ad Shidyaq, qui embrasse de plein gré la morale puritaine avant d'être poursuivi par ses anciens coreligionnaires, et qui meurt finalement dans des circonstances tragiques, fidèle à sa nouvelle foi. Ce récit de missionnaires révèle, à lui seul et sans décoration aucune, les enjeux innombrables d'un siècle crucial qui voit poindre ce que l'on appelle la modernité.

2 L'histoire, à vrai dire, peut se lire de différentes manières. Elle relate un épisode marquant de l'histoire de l'expansion culturelle et religieuse des États-Unis dans le monde. Bercés par le rêve d'une société idéale, d'une communauté chrétienne universelle, les milieux protestants américains sont en même temps conscients de la nécessité d'œuvrer avec acharnement pour l'avènement de la nouvelle ère. À la base de cette pensée se trouve un livre qui fit date au XVIII ${ }^{\mathrm{e}}$ siècle, Magnalia Christi Americana de Cotton Mather. Il consiste en une narration épique de la conquête de la NouvelleAngleterre et de la christianisation des Indiens entre 1620 et 1698 par John Eliot, stratège et figure exemplaire $\mathrm{du}$ missionnaire selon Mather. Un siècle après ces événements, les États-Unis commencent à déployer de réels efforts diplomatiques, culturels et «spirituels" dans la poursuite de leur but. Les agents de cette transformation, les missionnaires, étaient dotés d'une éducation rigoureuse qui les préparait à soutenir la foi puritaine contre «non seulement les athées et les infidèles, mais aussi les juifs, les mahométans, les arianistes, (...) les unitaristes et les universalistes, et toutes les autres hérésies et erreurs " s'opposant à l'Évangile du Christ, et dangereuses pour l'âme des humains (p. 58). 
3 À l'opposé, la perspective maronite peut être comprise à la lumière de la célèbre chronique du patriarche Istifan Duwayhi (1630-1704), Tarikh al-Azmina (« Histoire des Âges »), ironiquement contemporaine de celle de Mather. Ironiquement, parce qu'elle dépeint une vision du monde aux antipodes de celle des missionnaires. Une histoire centrée autour d'une communauté maronite profondément attachée à ce qu'elle croit être les vrais enseignements des saints apôtres et Pères de l'Église, revendiquant l'unité sans faille avec Rome; une communauté entourée par un "chaos de confessions", évoluant au sein d'un Empire ottoman mû par la Loi de l'islam, qui tolère et soumet à la fois toutes sortes de communautés « schismatiques » et hétérodoxes, à savoir chrétiens melkites, jacobites, latins, arméniens, aussi bien que juifs, druzes, musulmans chiites, etc. Tarikh al-Azmina est emblématique d'un tel contexte, où chacun pense avoir raison, où la coexistence est acceptée avec résignation (p.43). Cette "grammaire de l'hérésie " (p. 32) n'est cependant pas nouvelle, elle remonte à plus de deux siècles. Elle est très prégnante dans les écrits d'un autre auteur maronite, Jibra'il ibn al-Qila'i ( $† 1516)$, qui, après un séjour de vingt-trois ans en Italie pendant lequel il avait étudié la théologie, la science et les langues occidentales, revient sur sa terre natale. Ibn al-Qila'i fut à maints égards un missionnaire pour son propre peuple. Il s'employa activement à maintenir les membres de sa communauté fermement réunis autour de leur Église, produisant un grand nombre d'épîtres et d'admonestations contre les « incroyants » et les nombreux " hérétiques ». Le patriarche Duwayhi relaie et réadapte le discours d'Ibn al-Qila'i et ne tarit pas d'éloges à son égard. Mais ce que l'on retrouve surtout chez lui, c'est une profonde exaltation de la survie de l'Église maronite nonobstant les impitoyables dominations islamiques successives.

4 Lorsque les premiers missionnaires américains arrivent au Mont-Liban en 1820, ils ne tardent pas à rencontrer les autorités religieuses chrétiennes locales. Ils sont reçus avec la plus grande hospitalité par le patriarche maronite Yusuf Hubaysh. Néanmoins, dès qu'ils s'activent à leur tâche, les relations dégénèrent. On assiste à un choc frontal entre deux logiques radicalement antithétiques, deux doctrines aussi intransigeantes l'une que l'autre; d'un côté, une Église clamant sa perpétuelle orthodoxie, triomphante des épreuves et des tribulations épiques de l'histoire grâce à la Providence divine, et de l'autre côté une Église bercée par le rêve d'un renouveau christique universel, portée par l'élan de la conquête et de la victoire... Cette rencontre fondatrice, pour les uns et les autres, se résume dans la parabole d'As'ad Shidyaq.

5 Shidyaq avait fait ses études au collège de "Ayn Waraqa (calqué sur le modèle du Collège maronite de Rome), qui était chargé de dispenser un enseignement maronite classique et rigoureux. Le jeune homme possédait donc une excellente éducation par rapport à son époque et avait toujours fait preuve de piété et de grand dévouement pour autrui. En 1825, à l'âge de vingt-sept ans, et à la suite de longues discussions théologiques avec les missionnaires, il embrasse la foi protestante, et choisit de l'annoncer à son peuple. L'Église maronite, voyant en la conversion d'un de ses fidèles les plus précieux une agression de la part d'intrus sournois et «ennemis de l'Église romaine» (p. 95), est alarmée. Sa réaction est immédiate: Shidyaq est interpellé par le patriarche et interrogé sur sa décision. Il explique et défend obstinément sa croyance. Constatant là une déviance irréversible, une folie, le patriarche le fait emprisonner dans un monastère situé dans la vallée escarpée de Qannubin, au cœur de la montagne libanaise. Confiné dans sa cellule, Shiyaq est livré à un conflit intérieur; dans sa conscience se joue le contraste fatal des valeurs et des structures sociales qui se 
confrontent. C'est un personnage extrêmement introspectif, ainsi qu'en témoigne la nature très intellectuelle de son évangélisme (il tient régulièrement un journal, chose extrêmement inhabituelle). Il finit par succomber à la tourmente cinq ans plus tard, excommunié par son ancienne Église. Les missionnaires sont alors convaincus que le courage et la lucidité d'As'ad ont fait de lui le premier martyr de la foi nouvelle, bien que sans preuves d'une éventuelle torture physique (pp. 151-152). Certains vont jusqu'à le surnommer le Luther syrien. Quant à l'Église maronite, il s'agit d'un épisode honteux dont elle a très longtemps désiré ne pas garder le souvenir.

En quoi l'ouvrage peut-il se lire de différentes manières ? D'abord, il n'y a nul doute qu'il s'inscrit dans la continuité de la réflexion initiée par Edward Said sur l'orientalisme et le colonialisme. Car, à un niveau plus profond, la conversion religieuse est un moyen parmi d'autres d'effectuer une conversion culturelle et " civilisationnelle». Les missionnaires étaient mandés dans un empire dont ils ne savaient rien. Ils projetaient plutôt leurs "paysages intérieurs", ceux d'un Orient archaïque et stagnant. Selon Makdisi, la cohérence du savoir, des jugements, des convictions et des représentations de l'Orient dépend de l'idéalisation de l'Amérique plus que de la simple orientalisation de l'Empire ottoman (p. 178). Ils étaient venus rétablir la lumière et la liberté individuelle pour «ceux qui étaient assis dans l'obscurité » (p.65). Ils étaient venus prêcher la religion dite universelle tout en se distinguant délibérément des populations indigènes. L'auteur redécouvre une pléthore de documents attestant de cette attitude contradictoire, ce qui laisse subsister peu de doutes quant à la dimension résolument culturelle de la "régénération spirituelle ». L'échec de ce premier contact entre un groupe d'Américains et un groupe de sujets ottomans est, ainsi que l'exprime l'auteur, surtout une tragédie américaine (p. 4). Les convertis seront effectivement très peu nombreux par rapport aux moyens mobilisés.

7 Ensuite, l'ouvrage touche au problème de l'identité dans le monde arabe. L'exceptionnalisme américain trouve son contrepoint dans l'exceptionnalisme maronite, pour lequel la question de l'identité est capitale. La domination islamique est en effet fondamentale dans la représentation que la communauté maronite se fait d'elle-même (p. 39). L'identité maronite s'est construite avant tout par rapport à une profusion d'altérités. Que dire lorsqu'elle se voit confrontée à une «nouvelle dissidence ", qui plus est introduite par des étrangers ?

8 L'histoire d'As'ad Shidyaq sera racontée trente ans après sa mort, par un autre Libanais converti au protestantisme, et grand érudit de son temps, Butrus al-Bustani. Celui-ci, écrit Makdisi, est un produit exemplaire de la rencontre entre les histoires américaine et arabe qui légitima de nouvelles identités (p. 215), à l'heure où l'Empire ottoman est également pénétré par les idées de l'Europe. Bustani préconisera une vision libérale de la coexistence, avant que la rupture avec le groupe de missionnaires du XIXe siècle ne soit consommée, des années plus tard, par les évangéliques américains eux-mêmes. En 1920, le pasteur Howard Bliss, président du Syrian Protestant College (devenu American University of Beirut), proclame l'avènement d'une mission moderne caractérisée par l'acceptation de la différence et la sympathie à l'égard de toutes les religions.

9 La « tragédie américaine » que rapporte Ussama Makdisi, et dont les plus subtils détails sont étayés par une documentation très riche et intelligente, se termine à demi comme une histoire américaine, c'est-à-dire avec un happy ending. À demi, parce que le rêve de la coexistence est plus que jamais nécessaire dans les contrées du monde arabe où perdurent encore de nos jours les enjeux infinis du XIX siècle. 